\title{
Structure and magnetic properties of $\mathrm{Nd}_{2} \mathrm{Co}_{17-x} \mathrm{Ga}_{x}$ compounds studied by magnetic measurements and neutron diffraction
}

\author{
O. Moze ${ }^{\mathrm{a}}$, L. Giovanellib,1, W. Kockelmann ${ }^{\mathrm{c}, \mathrm{d}}$, C.H. de Groot ${ }^{\mathrm{e}}$, F.R. de Boer ${ }^{\mathrm{e}}$, \\ K.H.J. Buschow ${ }^{\mathrm{e}, *}$
}

${ }^{a}$ Istituto Nazionale per la Fisica della Materia, Dipartimento di Fisica, Universit'a di Modena,Via G. Campi 213/a, I-41100 Modena, Italy

${ }^{\mathrm{b}}$ Dipartimento di Fisica, Universit'a di Parma, Viale delle Scienze, I-43100 Parma, Italy

${ }^{\mathrm{c}}$ Mineralogical-Petrological Institute, University of Bonn, D-53115, Bonn, Germany

'ISIS, Rutherford Appleton Laboratory, Chilton, Didcot, Oxfordshire OX11 0QX, UK

${ }^{\mathrm{e}}$ Van der Waals-Zeeman Institute, University of Amsterdam, Valckenierstraat 65, 1018 XE Amsterdam, Netherlands

Received 18 May 1998; received in revised form 6 July 1998

\begin{abstract}
The structural properties of $\mathrm{Nd}_{2} \mathrm{Co}_{17-x} \mathrm{Ga}_{x}$ compounds $(x=5,6$ and 7) were studied by means of neutron diffraction. The refinement results of the neutron powder diffraction patterns show that the Ga atoms completely avoid the $9 \mathrm{~d}$ site in the rhombohedral $\mathrm{Th}_{2} \mathrm{Zn}_{17}$ structure. Furthermore, the $\mathrm{Ga}$ atoms increasingly occupy the $6 \mathrm{c}$ and $18 \mathrm{f}$ sites at the cost of the $18 \mathrm{~h}$ site that shows a decreasing Ga occupancy in this concentration range. At $4.2 \mathrm{~K}$, the easy magnetisation direction is perpendicular to the $c$-axis for $x=5$ and 6 , but parallel to the $c$-axis for $x=7$. From magnetic measurements and neutron diffraction it is derived that the $\mathrm{Co}$ and $\mathrm{Nd}$ moments at $4.2 \mathrm{~K}$ strongly decrease with increasing Ga concentration. There is also a strong decrease of the Curie temperature with Ga increasing concentration. (C) 1998 Elsevier Science B.V. All rights reserved.
\end{abstract}

PACS: $75.25 ; 75.30 ; 75.30 . \mathrm{G}$

Keywords: Rare earth cobalt intermetallics; Crystal structure; Magnetic properties; Magnetic structure; Neutron diffraction

\section{Introduction}

In a previous investigation, the magnetic properties of several series $\mathrm{R}_{2} \mathrm{Co}_{17-x} \mathrm{Ga}_{x}$ compounds

\footnotetext{
* Corresponding author. Tel.: + 31-20-525-5788; e-mail: buschow@nunleus.phys.uva.nl.

${ }^{1}$ Present address: Max-Planck-Institut für Metallforschung, Heisenbergstrasse 1, D-70569 Stuttgart, Germany.
}

were studied by means of magnetic measurements and X-ray diffraction on magnetically aligned powders, including series in which the rare earth component is $\operatorname{Pr}[1,2], \mathrm{Sm}, \mathrm{Gd}[3], \mathrm{Tb}$ [4], Y, Dy [5,6] and Ho [7]. These measurements have shown that increasing $\mathrm{Ga}$ concentration may lead in some cases to a sign reversal of the magnetocrystalline Co-sublattice anisotropy from easy-plane anisotropy for low Ga concentration to easy-axis 
anisotropy for higher $\mathrm{Ga}$ concentration. From a neutron diffraction study performed on several $\mathrm{Tb}_{2} \mathrm{Co}_{17-x} \mathrm{Ga}_{x}$ compounds [4] we have obtained evidence that also the rare earth sublattice anisotropy may give rise to a sign change with increasing $\mathrm{Ga}$ concentration. In the present study we have extended the investigation of $\mathrm{R}_{2} \mathrm{Co}_{17-x} \mathrm{Ga}_{x}$ to compounds with $\mathrm{R}=\mathrm{Nd}$ which we studied by magnetic measurements and also by neutron diffraction.

\section{Experimental}

The $\mathrm{Nd}_{2} \mathrm{Co}_{17-x} \mathrm{Ga}_{x}$ samples were prepared by arc melting starting materials of at least $99.9 \%$ purity. After arc melting the samples were wrapped into Ta foil, sealed into an evacuated quartz tube and annealed for three weeks at $900^{\circ} \mathrm{C}$. The X-ray diffraction diagrams showed that the annealed samples were single phase within the detection limit of the $\mathrm{X}$-ray diffraction, their crystal structure corresponding to the rhombohedral $\mathrm{Th}_{2} \mathrm{Zn}_{17}$ structure type.

The neutron powder diffraction experiments were made on the ROTAX high-intensity powder diffractometer, a facility present at the ISIS spallation neutron source [8]. Data were collected in the backscattering mode $\left(2 \Theta=124.5^{\circ}\right)$ and forward scattering mode $\left(2 \Theta=37.5^{\circ}\right)$ over the entire $20 \mathrm{~ms}$ time frame between ISIS pulses, providing a range of accessed d-spacings from 0.4 to $15 \AA$. For measurements in the paramagnetic regime, data were taken at room temperature for the $\mathrm{Nd}_{2} \mathrm{Co}_{17-x} \mathrm{Ga}_{x}$ compounds with $x=6$ and 7. For the compound with $x=5$ the data were taken at $400 \mathrm{~K}$, which is sufficiently high above the Curie temperature (see below). All compounds were investigated also at $4.2 \mathrm{~K}$.

The magnetic measurements were made on powdered material on a SQUID magnetometer in the temperature range $5-300 \mathrm{~K}$ in magnetic fields up to $6 \mathrm{~T}$. The measurements above $300 \mathrm{~K}$ were made on a home-built (Amsterdam) magnetometer based on the Faraday principle, using polycrystalline lumps in order to avoid oxidation at elevated temperatures as far as possible.

\section{Results}

The $\mathrm{Nd}_{2} \mathrm{Co}_{17-x} \mathrm{Ga}_{x}$ compound with $x=5$ has its Curie temperature above room temperature so that it was possible to take X-ray diffraction data on a magnetically aligned sample. From the enhancement of the 300 and 220 reflections and the simultaneous disappearence of the other reflections it was derived that this compound has an easy magnetisation direction perpendicular to the $c$-axis at room temperature.

Examples of neutron diffraction diagrams are shown in Figs. 1 and 2. The powder neutron diffraction data were analysed by the Rietveld method [8]. The nuclear scattering lengths employed in the refinement were $b_{\mathrm{Nd}}=0.769 \times 10^{-12} \mathrm{~cm}, b_{\mathrm{Co}}=$ $0.249 \times 10^{-12} \mathrm{~cm}$ and $b_{\mathrm{Ga}}=0.7288 \times 10^{-12} \mathrm{~cm}$. The results of the Rietveld refinements are presented in Table 1 for the data taken in the paramagnetic regime, and in Table 2 for the data taken at $4.2 \mathrm{~K}$.
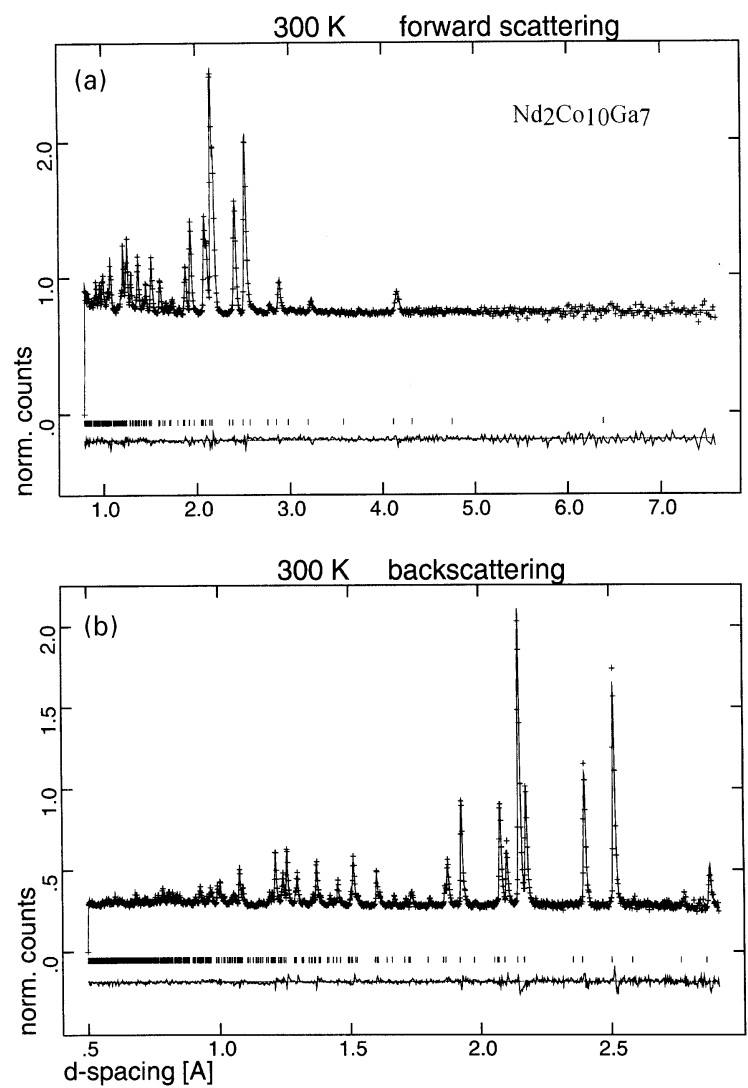

Fig. 1. Observed and calculated neutron diffraction pattern at $300 \mathrm{~K}$ for $\mathrm{Nd}_{2} \mathrm{Co}_{10} \mathrm{Ga}_{7}$ for forward scattering (a) and backscattering (b) detector banks. 

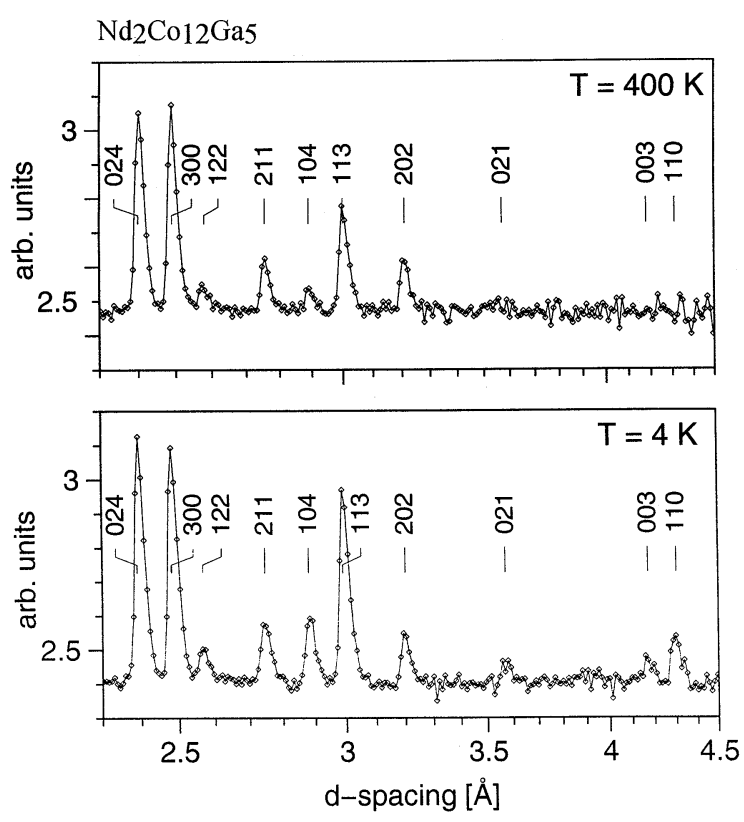

Fig. 2. Sections of the long d-spacing refined diffraction patterns for $\mathrm{Nd}_{2} \mathrm{Co}_{12} \mathrm{Ga}_{5}$ at 400 and $4 \mathrm{~K}$. The presence of a $\left(\begin{array}{lll}0 & 0 & 3\end{array}\right)$ reflection implies that this compound is planar at $4 \mathrm{~K}$.

Results of magnetic measurements showing the temperature dependence of the magnetisation are displayed in Fig. 3. It is seen that the magnetic ordering temperatures of the three $\mathrm{Nd}_{2} \mathrm{Co}_{17-x} \mathrm{Ga}_{x}$ compounds investigated decrease strongly with increasing Ga concentration.

The field dependence of the magnetisation at $4.2 \mathrm{~K}$ of the three $\mathrm{Nd}_{2} \mathrm{Co}_{17-x} \mathrm{Ga}_{x}$ compounds investigated is shown in Fig. 4. The spontaneous moments, $M_{0}$, obtained by extrapolation of the magnetic isotherms to zero field strength, have been listed in the last row of Table 2. The Ga substitution is seen to give rise to a fairly strong decrease of the magnetisation.

\section{Discussion}

In several previous investigations [9-13], neutron powder diffraction was used to study the site occupation of the non-magnetic elements $M$ in rare earth compounds of the type $\mathrm{R}_{2} \mathrm{Fe}_{17-x} \mathrm{M}_{x}$ $(\mathrm{M}=\mathrm{Al}, \mathrm{Ga}$ and $\mathrm{Si})$. In all examples studied, quite
Table 1

Refined neutron diffraction for $\mathrm{Nd}_{2} \mathrm{Co}_{17-x} \mathrm{Ga}_{x}$ data obtained at $400 \mathrm{~K}$ for $x=5$, and at $300 \mathrm{~K}$ for $x=6$ and 7 . Listed are the lattice constants, positional parameters and site occupancies. The Curie temperatures are given in the last row

\begin{tabular}{llll}
\hline Compound $\quad \mathrm{Nd}_{2} \mathrm{Co}_{12} \mathrm{Ga}_{5}$ & $\mathrm{Nd}_{2} \mathrm{Co}_{11} \mathrm{Ga}_{6}$ & $\mathrm{Nd}_{2} \mathrm{Co}_{10} \mathrm{Ga}_{7}$
\end{tabular}

\begin{tabular}{lccc}
\hline$a(\AA)$ & $8.60111(15)$ & $8.62115(9)$ & $8.69658(8)$ \\
$c(\AA)$ & $12.5103(5)$ & $12.48840(27)$ & $12.44132(23)$ \\
$V_{\text {cell }}\left(\AA^{3}\right)$ & $801.509(5)$ & $803.837(21)$ & $814.882(19)$ \\
$\mathrm{Nd}, 6 \mathrm{c}, z$ & $0.3414(5)$ & $0.34428(28)$ & $0.34913(24)$ \\
$\mathrm{Co} / \mathrm{Ga}, 6 \mathrm{c}, z$ & $0.0961(8)$ & $0.09922(37)$ & $0.10901(29)$ \\
$\mathrm{Co} / \mathrm{Ga}, 18 \mathrm{f}, x$ & $0.2888(5)$ & $0.29549(0)$ & $0.30328(23)$ \\
$\mathrm{Co} / \mathrm{Ga}, 18 \mathrm{~h}, x$ & $0.5023(4)$ & $0.50220(23)$ & $0.50215(25)$ \\
$\mathrm{Co} / \mathrm{Ga}, 18 \mathrm{~h}, z$ & $0.1531(4)$ & $0.15242(0)$ & $0.15214(29)$ \\
$\% \mathrm{Ga}, 6 \mathrm{c}, z$ & $14.7(15)$ & $39.7(10)$ & $73.4(10)$ \\
$\% \mathrm{Ga}, 9 \mathrm{~d}$ & 0.0 & 0.0 & 0.0 \\
$\% \mathrm{Ga}, 18 \mathrm{f}$ & $34.3(12)$ & $42.9(7)$ & $62.3(8)$ \\
$\% \mathrm{Ga}, 18 \mathrm{~h}$ & $38.5(11)$ & $37.8(6)$ & $27.5(2)$ \\
$R_{\mathrm{wp}}$ & 0.0166 & 0.0188 & 0.0290 \\
$R_{\text {exp }}$ & 0.0111 & 0.0286 & 0.0205 \\
$\chi^{2}$ & 1.553 & 1.269 & 1.303 \\
$T_{\mathrm{C}}(\mathrm{K})$ & 350 & 175 & 45 \\
\hline
\end{tabular}

Table 2

Refined neutron diffraction data obtained for $\mathrm{Nd}_{2} \mathrm{Co}_{17-x} \mathrm{Ga}_{x}$ at 4.2 K: lattice constants, positional parameters and magnetic moments. At the bottom of the table the refined values of the moment per formula unit $(M)$ are compared with the spontaneous moments $\left(M_{0}\right)$ derived from the magnetic isotherms at $5 \mathrm{~K}$

\begin{tabular}{lccc}
\hline Compound & $\mathrm{Nd}_{2} \mathrm{Co}_{12} \mathrm{Ga}_{5}$ & $\mathrm{Nd}_{2} \mathrm{Co}_{11} \mathrm{Ga}_{6}$ & $\mathrm{Nd}_{2} \mathrm{Co}_{10} \mathrm{Ga}_{7}$ \\
\hline$a(\AA)$ & $8.56478(0)$ & $8.60842(0)$ & $8.684266(0)$ \\
$c(\AA)$ & $12.46233(36)$ & $12.46833(48)$ & $12.41713(58)$ \\
$V_{\text {cell }}\left(\AA^{3}\right)$ & 791.70 & 800.21 & 810.99 \\
$\mathrm{Nd}, 6 \mathrm{c}, z$ & $0.3429(12)$ & $0.3444(12)$ & $0.35060(79)$ \\
$\mathrm{Co} / \mathrm{Ga}, 6 \mathrm{c}, z$ & $0.0976(14)$ & $0.0983(14)$ & $0.1080(10)$ \\
$\mathrm{Co} / \mathrm{Ga}, 8 \mathrm{f}, x$ & $0.2896(10)$ & $0.29003(98)$ & $0.30569(78)$ \\
$\mathrm{Co} / \mathrm{Ga}, 18 \mathrm{~h}, x$ & $0.50151(94)$ & $0.49972(92)$ & $0.4985(10)$ \\
$\mathrm{Co} / \mathrm{Ga}, 18 \mathrm{~h}, z$ & $0.1535(10)$ & $0.1529(11)$ & $0.1471(10)$ \\
$R_{\mathrm{wp}}$ & 0.0172 & 0.0178 & 0.0165 \\
$R_{\text {exp }}$ & 0.0168 & 0.0191 & 0.0188 \\
$\chi^{2}$ & 1.05 & 0.87 & 0.77 \\
$\mu, \mathrm{Nd}, 6 c, \mu_{\mathrm{B}}$ & $2.99(25)^{\mathrm{a}}$ & $2.11(30)^{\mathrm{a}}$ & $1.42(26)^{\mathrm{b}}$ \\
$\mu, \mathrm{Co}, 6 \mathrm{c}, \mu_{\mathrm{B}}$ & $1.85(31)^{\mathrm{a}}$ & $1.5^{\mathrm{c}}$ & $1.5^{\mathrm{c}}$ \\
$\mu, \mathrm{Co}, 9 \mathrm{~d}, \mu_{\mathrm{B}}$ & $0.85(19)^{\mathrm{a}}$ & $1.07(18)^{\mathrm{a}}$ & $0.45(19)^{\mathrm{b}}$ \\
$\mu, \mathrm{Co}, 18 \mathrm{f}, \mu_{\mathrm{B}}$ & $0.78(25)^{\mathrm{a}}$ & $1.22(33)^{\mathrm{a}}$ & $0.15(50)^{\mathrm{b}}$ \\
$\mu, \mathrm{Co}, 18 \mathrm{~h}, \mu_{\mathrm{B}}$ & $1.08(31)^{\mathrm{a}}$ & $0.60(32)^{\mathrm{a}}$ & $0.78(15)^{\mathrm{b}}$ \\
$M /$ f.u., $\mu_{\mathrm{B}}$ & 18.8 & 15.6 & 8.5 \\
$M_{0} / \mathrm{f} . \mathrm{u} ., \mu_{\mathrm{B}}$ & 17.0 & 12.4 & 7.9 \\
\hline
\end{tabular}

\footnotetext{
${ }^{a}$ Magnetic moments oriented along [ $\left[\begin{array}{lll}1 & 0 & 0\end{array}\right]$.

${ }^{\mathrm{b}}$ Magnetic moments oriented along [ $\left[\begin{array}{lll}0 & 0 & 1\end{array}\right]$.

${ }^{\mathrm{c}} \mathrm{Co}$ moments fixed during refinements.
} 


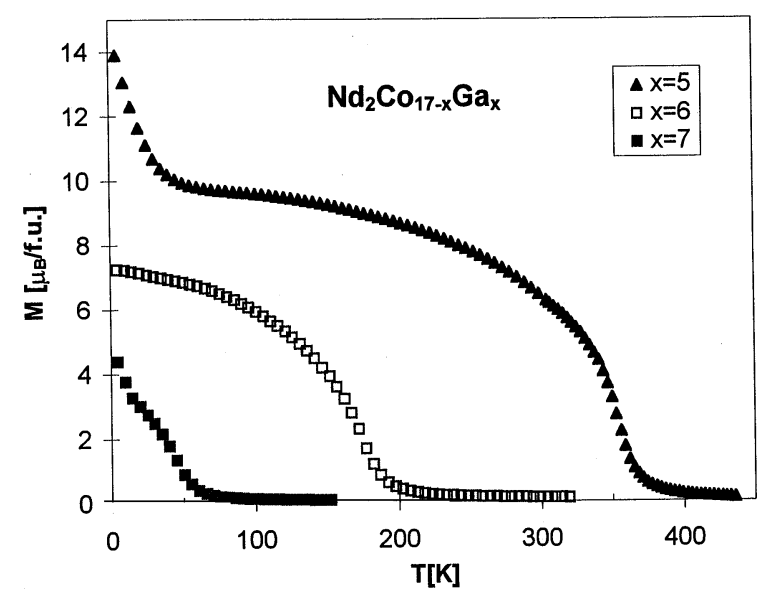

Fig. 3. Temperature dependence of the magnetisation of $\mathrm{Nd}_{2} \mathrm{Co}_{17-x} \mathrm{Ga}_{x}$ compounds measured in a field of $0.1 \mathrm{~T}$.

substantial deviations from a statistical site distribution of the non-magnetic atoms over the four available Fe sites (6c, 9d, 18f and 18h) were observed. A similar strong deviation from a statistical distribution is observed also in the compounds studied in the course of the present investigation. This can be seen more clearly in Fig. 5 where we

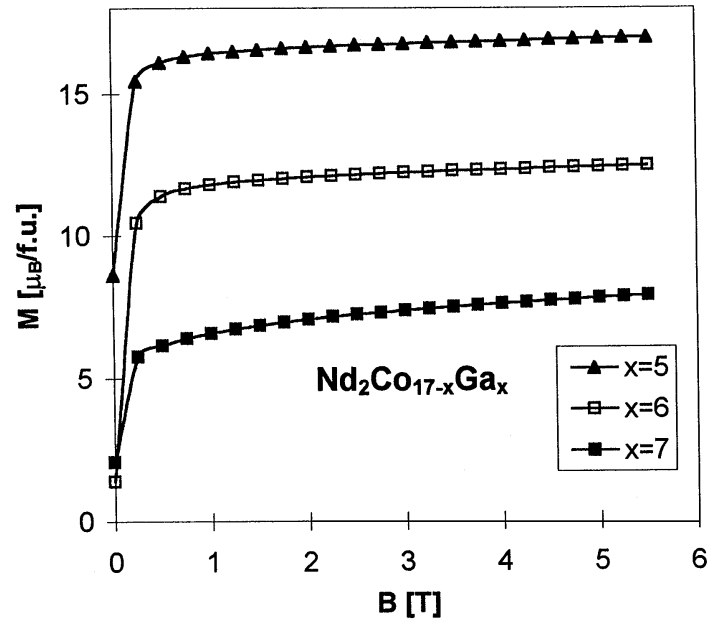

Fig. 4. Field dependence of the magnetic moment of $\mathrm{Nd}_{2} \mathrm{Co}_{17-x} \mathrm{Ga}_{x}$ compounds measured at $4.2 \mathrm{~K}$ with decreasing field.

have plotted the site occupations derived from the refinement of the neutron data listed in Table 1.

Generally, it is to be expected that the Ga occupancy of a given site increases with increasing Ga concentration. This behaviour is followed by the $6 \mathrm{c}$ and $18 \mathrm{f}$ sites, indeed. By contrast, the $9 \mathrm{~d}$ site appears to be extremely reluctant to accept any $\mathrm{Ga}$

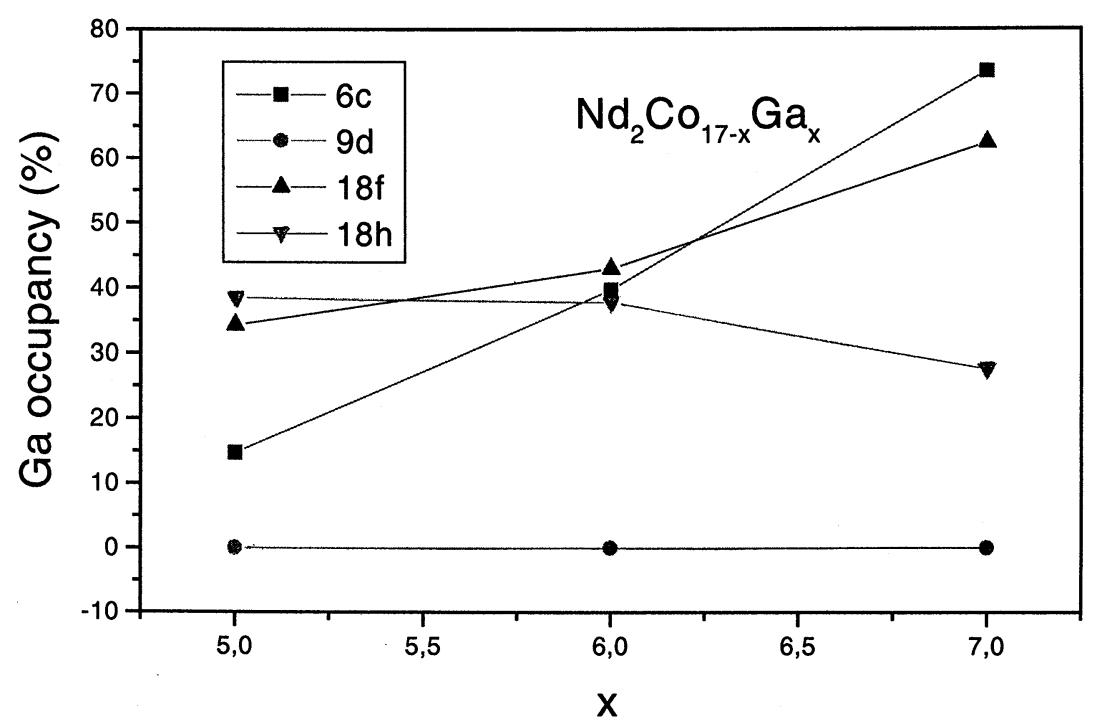

Fig. 5. Concentration dependence of $\mathrm{Ga}$ atom occupation of the four available sites in the $\mathrm{Th}_{2} \mathrm{Zn}_{17}$-type structure of the $\mathrm{Nd}_{2} \mathrm{Co}_{17-x} \mathrm{Ga}_{x}$ compounds. 
atoms. The by far most prominent feature of the results shown in Fig. 5 is that the Ga atoms occupation for the $18 \mathrm{~h}$ site decreases with increasing $\mathrm{Ga}$ concentration. In fact, the results shown in Fig. 5 can be taken as a further confirmation of the tendency of $\mathrm{R}_{2} \mathrm{Co}_{17-x} \mathrm{Ga}_{x}$ systems to form a true ternary compound at the composition $\mathrm{R}_{2} \mathrm{Co}_{9} \mathrm{Ga}_{8}$ in which the Ga occupancy is restricted to the $6 \mathrm{c}$ and $18 \mathrm{f}$ sites.

The tendency to form a ternary compound of the type mentioned above is not restricted to the Co compounds but was also observed for Fe compounds. Neutron diffraction studies made on $\mathrm{Tb}_{2} \mathrm{Fe}_{17-x} \mathrm{Ga}_{x}$ compounds [13] showed that the Ga atoms avoid the $9 \mathrm{~d}$ site completely and that the $6 \mathrm{c}$ and $18 \mathrm{f}$ sites become almost fully occupied by $\mathrm{Ga}$ atoms for $\mathrm{Ga}$ concentrations exceeding $x=8$. In all $\mathrm{R}_{2} \mathrm{Fe}_{17-x} \mathrm{Ga}_{x}$ compounds investigated thusfar the concentration dependence of the Curie temperature forms a maximum at about $x=3$ and decreases for higher $\mathrm{Ga}$ concentrations. However, beyond $x=7$ further Ga substitution leads again to an increase in Curie temperature. This surprising feature and the decrease in line broadening of the ${ }^{57} \mathrm{Fe}$ Mössbauer spectra in this concentration range are further indications of the tendency to ternary compound formation [13].

Results of the refinements pertaining to the magnetically ordered regime are given in Table 2 . The moment of the Co atoms occupying the $6 \mathrm{c}$ sites were fixed in this refinement because of the low multiplicity of the $6 \mathrm{c}$ sites. For the other Co moments one may notice a tendency to decrease with increasing $\mathrm{Ga}$ concentration within experimental error. This is reflected also in the values of the total moment per formula unit, listed at the bottom of the table. The latter values are in fair agreement with the spontaneous moments derived from the magnetic measurements, given in the last row of Table 2 .

The decrease in moment per formula unit is seen in the Table 2 to be partly caused by the strong decrease of the $\mathrm{Nd}$ moment. These results show that crystal field interactions are presumably fairly strong in these materials. In the compound with $x=5$ the comparatively large Co moments and large number of $\mathrm{Co}$ atoms probably lead to an exchange splitting of a magnitude comparable to the crystal field splitting so that the $\mathrm{Nd}$ moments are only slightly below the free ion value. Evidently, in the compound with $x=7$ the crystal-field splitting dominates.

The Co sublattice anisotropy in $\mathrm{R}_{2} \mathrm{Co}_{17-x} \mathrm{Ga}_{x}$ systems is still a matter of controversy. For instance, the preferred moment direction in $\mathrm{Gd}_{2} \mathrm{Co}_{17}$ is perpendicular to the $c$-axis [14], but results of $\mathrm{X}$-ray diffraction made on magnetically aligned $\mathrm{Gd}_{2} \mathrm{Co}_{17-x} \mathrm{Ga}_{x}$ samples with $x \geqslant 2$ showed that the easy magnetisation direction at room temperature corresponds to the $c$-axis in these compounds, meaning that the Co sublattice anisotropy changes sign from negative to positive with increasing $\mathrm{Ga}$ concentration [3]. By contrast, similar studies made on magnetically aligned $\mathrm{Y}_{2} \mathrm{Co}_{17-x} \mathrm{Ga}_{x}$ samples showed that no such sign reversal of the Co sublattice anisotropy occurs in this system [6]. It is therefore difficult to make any prediction regarding the Co sublattice anisotropy in the $\mathrm{Nd}_{2} \mathrm{Co}_{17-x} \mathrm{Ga}_{x}$ compounds. Anyhow, the X-ray diffraction observation of an easy-plane anisotropy in the compound with $x=5$ at room temperature indicates that even if the Co sublattice has uniaxial anisotropy for this composition, it is dominated by the planar anisotropy of the $\mathrm{Nd}$ sublattice. From the refinement of the neutron data shown in Table 2 it can be derived that this situation persists down to $4.2 \mathrm{~K}$. The upturn in the temperature dependence of the magnetisation seen below about $45 \mathrm{~K}$ in Fig. 3 is probably due a weakening of the $\mathrm{Nd}$ sublattice anisotropy below this temperature. This upturn disappears completely when the magnetisation is measured in much higher fields than applied in Fig. 3.

It can be seen in Table 2 that the easy magnetisation direction is perpendicular to the $c$-axis at $4.2 \mathrm{~K}$ also in the compound with $x=6$. Surprisingly, however, the easy magnetisation direction is parallel to the $c$-axis in the compound with $x=7$. Owing to the fact that the rare earth sublattice always predominates the $3 \mathrm{~d}$ sublattice anisotropy in this class of materials at low temperatures, the concentration dependent change in easy magnetisation direction implies a change in the nature of the crystal field with increasing $\mathrm{Ga}$ concentration. A similar observation was recently made in neutron diffraction studies of $\mathrm{Tb}_{2} \mathrm{Co}_{17-x} \mathrm{Ga}_{x}$ compounds [4] and $\mathrm{Tb}_{2} \mathrm{Fe}_{17-x} \mathrm{Ga}_{x}$ compounds [13]. In both 
systems increasing $\mathrm{Ga}$ concentration leads to a change from easy-plane anisotropy to easy-axis anisotropy. Noting that the second-order Stevens factor for $\mathrm{Tm}$ is different from that of $\mathrm{Nd}$ and $\mathrm{Tb}$, this change in anisotropy is consistent with that observed at low temperatures in $\mathrm{Tm}_{2} \mathrm{Fe}_{17-x} \mathrm{Ga}_{x}$ compounds where it changes fom easy axis to easy plane with increasing Ga concentration [15].

\section{Concluding remarks}

Using neutron diffraction and exploiting the large difference in scattering length between $\mathrm{Co}$ and Ga we have obtained reliable experimental information of the preferential site occupation of $\mathrm{Ga}$ in $\mathrm{Nd}_{2} \mathrm{Co}_{17-x} \mathrm{Ga}_{x}$ compounds $(5 \leqslant x \leqslant 7)$. With increasing $\mathrm{Ga}$ concentration the $18 \mathrm{~h}$ site becomes less occupied by Ga atoms, a fact that indicates that there is a tendency in this system to form a ternary compound of the composition $\mathrm{Nd}_{2} \mathrm{Co}_{9} \mathrm{Ga}_{8}$. We have confirmed results obtained in previous studies that increasing $\mathrm{Ga}$ concentration leads to drastic changes in the crystal-field interaction in $3 \mathrm{~d}$ compounds of the type $\mathrm{R}_{2} \mathrm{~T}_{17-x} \mathrm{Ga}_{x}$ to the extent that a sign reversal occurs in the rare earth sublattice anisotropy.

\section{Acknowledgements}

This work was partly financed by support from the TMR (Training and Mobility of Researchers) programme of the European Community. Financial support from the Italian National Research Council, Consiglio Nazionale delle Ricerche, and the Dutch Technology Foundation STW is also gratefully acknowledged.

\section{References}

[1] C. Zhang, J.C.P. Klaasse, E. Brück, F.R. de Boer, K.H.J. Buschow, J. Alloys Compounds 266 (1998) 43.

[2] S.-Y. Zhang, B.-G. Shen, B. Liang, Z.-H. Cheng, F.-W. Wang, H.-W. Zhang, Solid State Commun. 104 (1998) 732.

[3] D. Zhang, D.P. Middleton, E. Brück, F.R. de Boer, Z.D. Zhang, K.H.J. Buschow, J. Alloys Compounds 259 (1997) 65.

[4] O. Moze, L. Giovanelli, W. Kockelmann, C.H. de Groot, F.R. de Boer, K.H.J. Buschow, J. Alloys Compounds 266 (1998) 43.

[5] S.Y. Zhang, B.G. Shen, B. Liang, Z.H. Cheng, J.X. Zhang, H.W. Zhang, J.G. Zhao, W.S. Zhan, J. Alloys Compounds 264 (1998) 19.

[6] C. Zhang, E. Brück, F.R. de Boer, K.H.J. Buschow, J. Alloys Compounds 270 (1998) 78.

[7] C. Zhang, J.C.P. Klaasse, E. Brück, F.R. de Boer, K.H.J. Buschow, J. Alloys Compounds 267 (1998) 37.

[8] W. Schäfer, E. Jansen, R. Skowronek, G. Will, W. Kockelmann, W. Schmidt, H. Tietze-Jaensch, Nucl. Instr. and Meth. A 364 (1995) 179.

[9] G.J. Long, G.K. Marasinghe, O.A. Pringle, Z. Hu, W.B. Yelon, D.P. Middleton, K.H.J. Buschow, F. Grandjean, J. Appl. Phys. 76 (1994) 5383.

[10] Z. Hu, W.B. Yelon, S. Mishra, G.J. Long, O.A. Pringle, D.P. Middleton, K.H.J. Buschow, F. Grandjean, J. Appl. Phys. 76 (1994) 443.

[11] D.P. Middleton, S.R. Mishra, G.J. Long, O.A. Pringle, Z. Hu, W.B. Yelon, F. Grandjean, K.H.J. Buschow, J. Appl. Phys. 78 (1995) 5568.

[12] H. Luo, Z. Hu, W.B. Yelon, S.R. Mishra, G.J. Long, O.A. Pringle, D.P. Middleton, K.H.J. Buschow, J. Appl. Phys. 79 (1996) 631.

[13] O.A. Pringle, G.J. Long, S.R. Mishra, D. Hautot, F. Grandjean, D.P. Middleton, K.H.J. Buschow, Z. Hu, H. Luo, W.B. Yelon, J. Appl. Phys. (1998) to appear.

[14] J.J.M. Franse, R.J. Radwanski, in: K.H.J. Buschow (Ed.), Handbook of Magnetic Materials, Vol. 7, North Holland, Amsterdam, 1993, p. 307.

[15] B.G. Shen, Z.H. Cheng, F.W. Wang, Q.W. Yan, H. Tang, B. Liang, S.Y. Zhang, F.R. de Boer, K.H.J. Buschow, S. Ridwan, J. Appl. Phys. 83 (1998) 5945. 